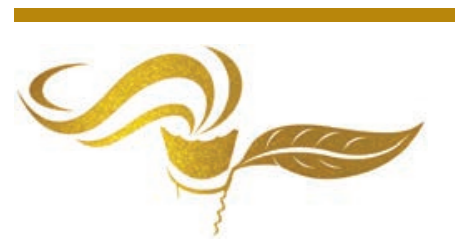

\title{
Ambassadors of the Sensible World
}

\section{Aurélien Gamboni}

Artist and researcher, teacher at Geneva School of Art and Design and guest speaker at Hochschule der Künste Bern, Switzerland

Received 5 February, 2020; Revised 6 March, 2020 Accepted 9 March 2020

Available online 9 March, 2020 at www.atlas-journal.org, doi: 10.22545/2020/0133

Me may work on things, but the opposite is perhaps even more true: things work on us. Reflecting on several projects of art and research that I have been involved in over the past years, which address different aspects of the environmental mutations currently in process, this paper will aim to partly divert from a usual focus on the deliberate intentions and goals that we can set ourselves as authors, rather observing how various objects of concern can progressively grow in our conscience and in our practice, calling for new transdisciplinary and investigative tools. These projects include the observation of a negotiation summit re-enacted at SciencesPo Paris in 2012, during which the "specter" of climate change seemed to appear in the room as an almost physical presence; the long term artistic research project "A tale as a tool" developed with anthropologist and writer Sandrine Teixido, involving a text of fiction as an investigative object of mediation, allowing to collect testimonies by members of frontline communities from the South of Brazil to the North of Norway; and the research project "The Anthropocene Atlas of Geneva" at Geneva school of Art and Design, gathering self-reflexive interviews with numerous scientists, artists and other actors of the ecological transition.

Keywords: anthropocene studies, artistic research, situated knowledge, transdisciplinarity, human-nonhuman assemblages, theories of attention.

\section{Introduction}

As artists or researchers we may work on things, but the opposite is also true: things work on us. Whatever object or phenomenon we aim to grasp, whatever matter to handle, they affect us in ways that cannot necessarily be measured nor described. They transform our conscience, or should we say, they precisely build it anew. Piece by piece. Contact after contact.

This movement seems motionless, yet it crushes the landscape of logic under glacial reveries. This slow flowage makes one conscious of the turbidity of thinking. Slump, debris slides, avalanches all take place within the cracking limits of the brain. The entire body is pulled into the cerebral sediment, where particles and fragments make themselves known as solid consciousness [1].

Robert Smithson 
As I started to write this paper, I wanted to reflect on several projects of art and research that I had been involved in over the past years, which addressed different aspects of the environmental mutations currently in process. In that regard, it seemed important to partly divert from a usual focus on the deliberate intentions and goals that we can set ourselves as "authors", rather observing how various objects of concern can progressively grow in our practice, overflowing disciplinary boundaries, stepping in unexpected contexts and enlisting unexpected actors.

In my case, this approach has proved to be a necessity. Generations of artists have been able draw their engagement either from an intimate knowledge of wildlife, from a parallel study background (e.g. in natural sciences), or from an extensive comprehension of ecological thinking and activism, among other kinds of precious experiences in the matter. For my part I had none, and like many, I came to realize that I was totally unprepared. Unprepared to the vastness of the changes that were occurring around me, unprepared to the complexity of these transformations and their countless implications, and finally unprepared to the difficulty of even perceiving them. Of course, this could be considered a widely shared condition, and there are many ways to experience what Isabelle Stengers and Bruno Latour called the "intrusion of Gaia" in human affairs [i, 2], described as an "a ticklish assemblage of forces that are indifferent to our reasons and our projects" [3], thwarting our plans and challenging our capacity of attention.

The following narrations are only moments in longer term projects, all of which are collaborative ones. The collective Save as draft for the first scene, Sandrine Teixido for the second, and my current colleagues at Geneva School of Art and Design for the third, all would certainly narrate the same events in quite different ways. Yet across all these different engagements, I will describe some of the moments during which my mental dispositions have been either challenged or affected by the very objects of my attention. The kind of moments in an investigation process where perceptions shift, representations are transformed and new relations appear. Issues appear knotted with other issues, being with other beings, up to constituting an indivisible fabric, not unlike the "string figures" evoked by Donna Haraway [4].

\section{The Unexpected Apparition of the (Climatic) Ghost in the Negotiation Room}

The large building of rue Saint Guillaume in the 7th arrondissement, emptied of all its usual activities, is now the scene of a strange ballet. People gather and disperse in the rooms, alleys and stairs. They write, talk and re-write the writings. So far, everything is going as planned, it may all be finished before the night falls.

Drafting sessions, plenary sessions, and corridor diplomacy: if there is one specter to evoke at this point, it would be that of COP 15, the 2009 UN summit of negotiation on climate change which was held in Copenhagen a year and a half before, and was quite univocally considered a huge failure. Yet, this is not the Bella Center but the historical building of Sciences Po in Paris, and instead of the 10,500 delegates of the initial event, almost 200 students are gathered here to re-enact the summit in a simulation process and to bring it to a new conclusion, hopefully a more ambitious one. [ii]

With my fellow companions observing the process, we had never seen anything quite like that. At some point, the level of engagement in the game had become so high that the frontiers between fiction and reality started to blur. Even our own role in that process was questioned that very night, when the crisis occurred. At first, it was a rather comfortable role: as a small group of artists and researcher from the Speap program [iii] - gathered under the name Save as Draft [iv] - we had proposed an observation protocol that could allow us to witness the translation of scientific objects into political objects, as we explicitly aimed for. We had selected two participants of the simulation - one from the delegation of India and one scientist from the IPCC group - that we equipped with a sound recording device, following them with a Go-Pro camera and taking detailed notes about their every movements, encounters and discussion. Rather than documenting the process at large, we intended to be at the best position to observe how specific objects of the negotiation would circulate within this context, how they would be described and transmitted from a person to another, from a room to another, from a medium to another, and how they would progressively 


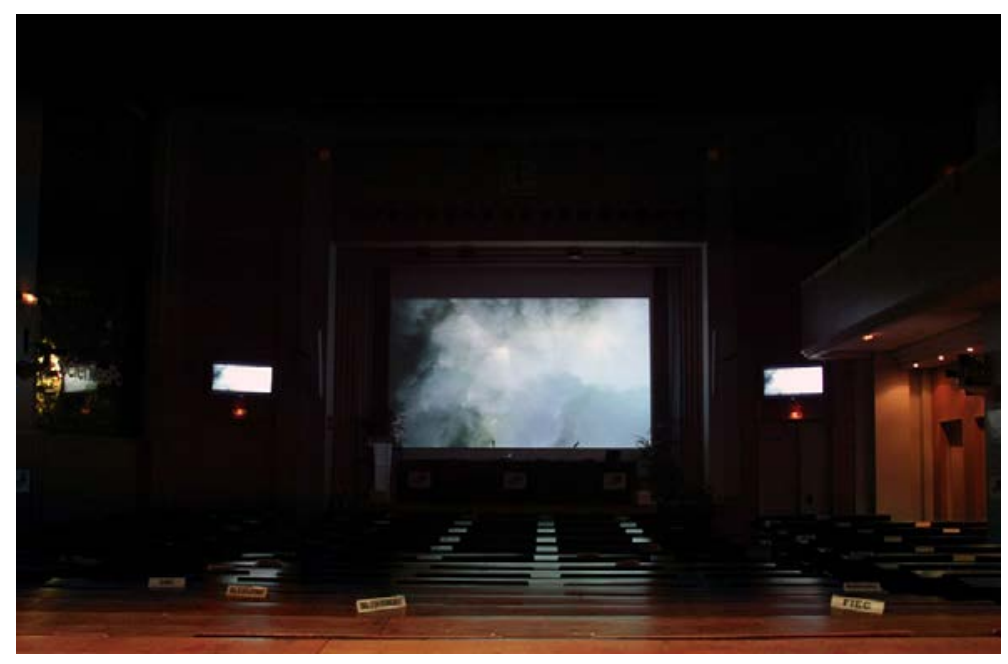

Figure 1: The emptied plenary session during the crisis of negotiation (Photo credit: Filipe Païs).

evolve and aggregate in that process, shrinking their way into the final draft of the resolution.

Since we also needed a fictional role, we were registered as journalists, entitled to circulate within all parts of the 3 floors building with a press badge. Inside our "headquarters", a small room equipped with computers, some of us would be permanently processing the material gathered by the "field" observers, sometimes exchanging roles. To be perfectly honest, I wasn't always totally comfortable during the three days of the event. The technicality of the matters discussed, even simplified for the purpose of the exercise, was challenging. Over the previous year, we had something like an accelerated training on the matter of climate change, both from some of the Speap guest lecturers and from the testimonies we had been personally gathering among scientists, negotiators and activists that had been involved in the real COP15 summit. In fact, every participant to this event had been preparing for a while, but in the end there was no preparation for the way things unfolded.

"We are all going to die!" If I recall correctly, the participant who pronounced these words was from the European delegation. It is now later in the night, and the whole situation looks transformed. The negotiation is on the verge of collapsing, and it doesn't look like a game anymore. "This is real, now!", tells me one of the coordinators of the Secretariat, as she prevents me from entering the crisis room were selected members of the delegations are now meeting. "No press allowed!" At first I simply don't understand what is happening, we were supposed to be observing the event and allowed to access all sessions, she has no right to block me! It will take me some time to realize that it is not just me and some others who are locked outside of the crisis room, but all of us, the 200 "players", who are now locked in this fictional space.

The "crisis", as it was later called, came from the fact that some among the participants had been doing their maths. Fittingly, it was the Indian delegate followed by Joffrey who first started redoing some of the calculations that had served as the basis for the simulation, soon joined by the IPCC member and a Venezuela representative. Trying to solve the challenge of both recognizing the legitimate "development" of countries of the Group 2, some of which are expecting a fast expanding demography, while keeping up with the reduction of greenhouse gases emissions to achieve the mitigation goals, had proved irreconcilable in their calculations. These were first made on a piece of paper, then repeated several times on the computer, gathering new people around it as the problem started to spread, calling for new meetings, shattering all basic forms of consensus that had been patiently built until then, interrupting the drafting sessions, and even emptying the recreational screening of Yann Arthus-Bertrand's movie "Home" from all its spectators (see Figure 1).

Still following the Indian delegate, Joffrey had been allowed inside the crisis room with a selected 
number of participants. With the others, I ended up witnessing the "press conference" that was held later on. Radical measures had been proposed in order to preserve the possibility for an agreement to take place, and guarantee the necessary funds to avoid the worse effects of climate change. The delegates from the World Bank and the World Trade Organization (also represented among the participants) were even the ones to promote a tax on financial transactions! Despite these efforts, it was acknowledged that the $2^{\circ} \mathrm{C}$ goal could probably not be achieved, which meant, among other dreadful consequences, that the Pacific islands could not be saved.

Of course, this was only a game [v]. Still, it was quite striking to consider that this event, based on the basic parameters of the COP15 that took place a year and a half before, would end up concluding that far more important means were necessary to achieve a significantly less ambitious result. As disturbing was the feeling that this all started to look somehow closer to reality than maybe the actual COP15 summit had been. There was now a sense that this massive and ungraspable object, or "hyperobject" as Timothy Morton would call it [5], was becoming palpable within the building of Saint-Guillaume street. A sense that climate change was appearing not as a mere object of negotiation, challenging the geo-political distribution of powers as it was being staged, but as a true actor, taking control of the event from now on. Like a specter, whose presence had been slowly growing between these walls as its name was being repeatedly evoked, but that nobody expected to show up.

The closing assembly of the simulation was finally approaching, and with my fellow companions we were expected to present a kind of performative feedback in that context. It had been a long night for everybody. After finally achieving a new agreement on the basis of the terms previously described, the delegations were now writing their final speech, which, in the case of the Pacific islands delegation, meant enacting their planned disappearance despite all the ambitious efforts conceded. I remember Joffrey and Simon in our headquarters, selecting the film footage of the exact moment when the first calculations were made that had led to the complete overturn of the whole process. I also remember Sandrine writing the text of our intervention, addressing this feeling of a new entity that had made irruption during the simulation. A "shapeless monster" was one of the terms she used.

On the moment, I am not sure that I entirely grasped what was at stake. Maybe none of us entirely did, in fact. Since then, many of the participants of that event, either the delegates or my fellow companions, have continued working on some of the environmental challenges of our time, including that of climate change. I wouldn't call this experience a revelation in a mystical sense, but it was certainly a transformative one, and we left with the strong feeling that something more than a mere exercise had taken place that week.

\section{Seismic Disruptions in the Subarctic Marine Soundscape}

We had passed several times close to Henningsvær, while driving on the E10 that crosses the Lofoten archipelago from West to East, but so far we hadn't taken the bridge to join the little island. Henningsvær is one of the many typical little towns of the Lofoten, with its setting of colourful fisherman's cabins. It also hosts a couple of restaurants, a caviar factory transformed into a museum, an "Arctic tattoo" shop and, right next to it, the sign "Ocean Sounds" hanging over an office door.

Heike Vester is a German biologist specialized in the communication of marine mammals. Sandrine and I are sitting in her office, explaining like we always do the somehow unusual reason of our presence in the region: We are doing an investigation based on Edgar Allan Poe's short story called "A descent into the maelström" - yes, that one about the three fishermen caught in the whirlpool. We came here to collect testimonies and narratives that can resonate with this story, regarding how we can perceive environmental threats, how we can build knowledge in situation of risks. We chose this region because it is the place where the real "malstrøm" is located, but we're also interested in the current local struggles against the development of the oil industry. More broadly, any forms of environmental knowledge related to this border region of the Arctic is of interest for us. [vi] 


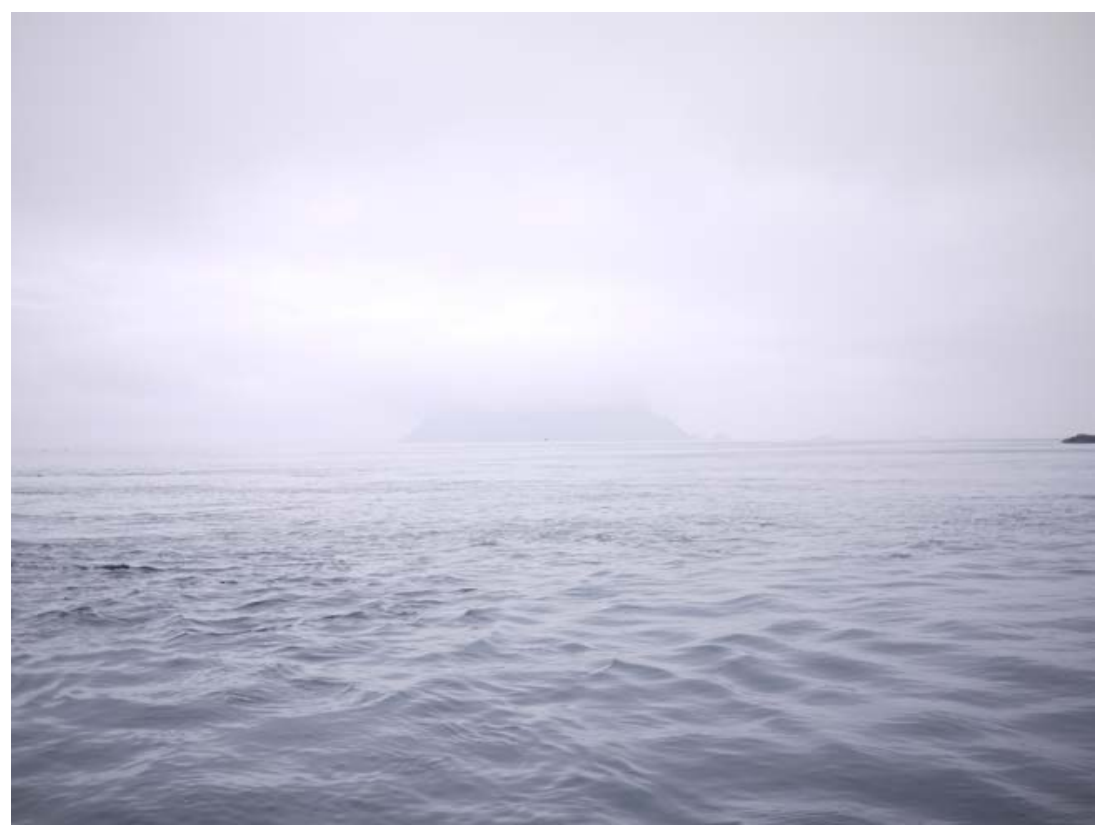

Figure 2: On the waters of the maelstrm, May 2014 (Photo credit: Teixido/Gamboni).

Like most of the people we encountered previously, whether natural scientists, eco-activists, historians, fishermen or state officers, Heike Vester is very well disposed to share about her experience. She first came in the region in the late 1990s and soon decided to stay, in order to study the pilot whales and killer whales, two extremely social and particularly vocal species. Since then, she has been tracing the presence of these whales as they come to the region, attracted by the vast numbers of cods coming to the fjord to spawn every year. Equipped with a hydrophone and a sound amplifier, she goes on boat in the fjord and records underwater soundscapes, to later analyze the high frequency conversations of these marine mammals [vii]. But of course, along with the whales come many other noises, and the soundscapes of what appears as an ideal research field also testifies to the growing impact of human activities.

\section{- When you are out there, you record everything, you study everything. You can't just study one thing. Nature is not like that.}

It is by mere chance that we came to meet her. A couple of days earlier, we had finally decided to join a touristic boat ride to the Moskenstraummen, the actual "malstrøm" that inspired Edgar A. Poe. Although our main focus was to collect testimonies, we certainly had to visit the phenomenon at the origin of our investigation. The trip had been both deceiving and fascinating. A deep fog had started to rise as soon as we passed the village of $\AA$, at the far end of the E10 road, to navigate alongside the ever wilder and craggier shores, closer to to the cliffs of Hellsegga. Once on the very spot, almost nothing was to be seen. The fog was complete, but it was also strangely bright, as if we were floating in a thick cloud of light (see Figure 2). It is precisely there, in the midst of this big nothingness, that they appeared, first as some elusive black shadows on the white sea, then more distinctly as the killer whales - four of five of them started to emerge. They turned around our boat and then accompanied us, even on our way back to the village of Reine. It was a lucky encounter: we knew that we probably wouldn't have come to the office of Ocean Sounds if we hadn't meet them on that day.

-You saw killer whales there? When?

-A few days ago, it should have been on Tuesday... 
Heike seems surprised, she wants us to explain exactly where we saw them, even asking to see our pictures. She is increasingly worried by the disturbances affecting the whales. In the conversation that follows, many of our understandings of the current situation in the Lofoten will be challenged. She starts playing a recording. Distinctly, we hear the marine soundscape being disturbed by a deep tremor, repeating every 8 or 9 seconds, relentlessly. [viii]

-When you're above water it's beautiful, silent, and then you hang in the hydrophone, and you hear... Right now, we hear a lot of the seismic shootings. Last week, we had three boats at the same time. And one is 500 kilometers away, the other 200, 300 kilometers away, and we hear it. And then the whales are gone...

-You hear the boats...?

-Seismic, for the oil. When they're looking for the oil, they use seismic air-guns. Seismic investigation. It travels for two thousand kilometers. And there's no regulation in Norway.

-But... Two thousand kilometers?

-Yes, it's the sea!

On the moment, this information seems difficult for us to process. The petroleum controversy in the region, focusing merely on the local implementation of offshore extraction platforms, and distributing the main positions between the defense of or resistance against these implementations, first seem to prevent us from conceptualizing this new dimension of the problem. The moratorium preventing oil explorations in the regions of Lofoten, Vesterålen and Senja is still valid when we meet Heike [ix], but this is not sufficient, as these seismic shootings performed hundreds (even thousands) of kilometers away for exploration purpose already have a huge impact here, as these sounds testify. Together, they even constitute "a sound wall all along the coast of Norway" as Heike calls it.

- So imagine, you come, you swim like you have always done, then you come to this area and you hear that sound. You don't know what it is, it could be an earthquake, it's such a high frequency, so loud. It's not a boat, they know boat noise, it's disturbing but they know it. Where does it come from, what is it? And it does cover communication, the same frequency is masking the communication of some of the whales and I see that they just go. Pilot whales, for the first time this year, they came and then after two days, they just left.

Like Poe's character in the tale, who cannot convince his fellow fishermen to believe his story after he survived the maelström, Heike has difficulties in having other people listen to these sounds. She tried to contact Greenpeace and the WWF, but at that time they're already mobilized to protect whales in other regions and the Lofoten islands are not a priority. She has proposed fishermen to join her on her boat and listen to these sounds, warning them that their fish "stocks" might also soon be affected, so far without success. The perception that the area is protected is still largely spread.

It's not protected, what are you talking about? You can't protect something that is already impacted! They keep going, but it's underwater. No one sees it, no one hears it. If I wouldn't be there with my hydrophone, no one would know.

As it often happens, widely covered controversies tend not only to polarize the opinions, but also to flatten the complexity of the problem and to render invisible some of the practices and experiences that don't fit in this picture. In that context, restituting some of this visibility becomes part of the investigative task. At that time, we are only on the verge of starting to hear about many of the specific changes occurring in the region, many of which constantly challenge the scale and the territorial constraints of our investigation. 


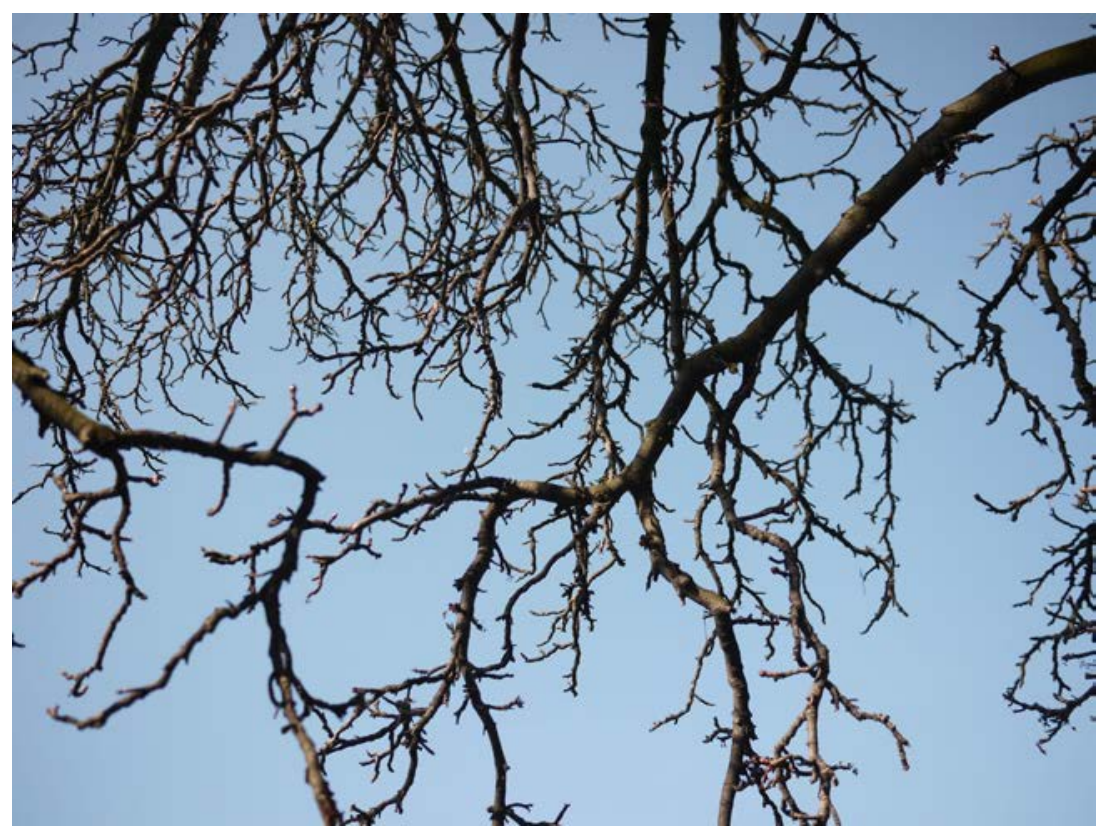

Figure 3: Observing leaf buds on the official Horse Chestnut tree.

Following the different leads encountered, our investigation map gets progressively populated by new beings and new problematics: from the warming of the sea, which implies that possibly the cod spawning might no longer happen in the Vesfjord in the future, displacing the whole fishing industry up-north, to the contaminants that follow the streams up to the vulnerable regions of the Arctic, connecting both areas as a jointly strategic marine ecosystem; from the fishing villages displaced during the modernization period in the 1950s to the suppressed memories of the coastal Samí populations in the area, both of which carried a precious environmental knowledge that few persons can revive. In the end it wasn't one issue against another, but an entanglement of inter-related issues that the investigation allowed to start discerning $[\mathrm{x}]$.

\section{An Alliance with a Ttree: Towards a (Situated) Anthropocene Atlas}

The weather is clement for the season, which is twice fortunate. First, because it will facilitate the little investigative tour that I have planned for our London guests [xi], and secondly because the tree might even come into leaf today, which would be a perfect coincidence. We all stand underneath its branches, observing the buds while waiting for our interviewee (see Figure 3).

Exactly how old is that Horse Chestnut tree, no one knows exactly. Its observation started in 1929, when he was elected to succeed to its predecessor, thus becoming Geneva's third "Marronnier officiel " since the beginning of this local tradition in 1818. An important role for an important tree, as the day when it first comes into leaf officially marks the beginning of Spring. During all the winter, it is the responsibility of the Sautier of the Republic of Geneva to observe its buds as they start getting shiny, one of the signs that they are about to open. And when the first bud finally comes into leaf, the Sautier makes an official announcement and inscribes the date on a handwritten record.

-During this period I come everyday, it's on my way. I like to see the marronnier all the time, and see how he's doing, because he's getting old. These days, I even come in the afternoon, because by experience - I've been doing this for 16 years 
now-, by experience I know that when the sun comes out in the afternoon and when it's warm like today, the bud might open.

Maria Anna Hutter is the 70th Sautier of the Republic, and the second woman at this very special position since the 15 th century. She enjoys evoking her relation with the aging marronnier, which is now leaning over the promenade's fence, over the road and the University park des Bastions, partly sustained by a large triangular metallic support. At our request, she accepts to show us the handwritten records of all previous dates of leafing, which is kept in a glass safe box in one of the assembly rooms of the Grand Council nearby. Inside the box, the old parchment, fixed on a large slice of wood, has been extended by a second piece of parchment on the verso. Looking at the dates on the first side - mostly covering the 19 th century - and then looking at the more recent ones, certainly offers a striking contrast. On the recto, mid March to mid April is the dominant period during which the trees come into leaf, while on the verso, it rather spans from mid February to mid March, sometimes even in January. Once, the buds even opened twice, starting in December: that was in 2002, the year before the memorable summer heatwave that, according to the evaluations, caused the death of around 70,000 persons in Europe [xii].

The official horse chestnut tree, a witness of climate change? After all this is not surprising: why wouldn't the tree be affected by the evolution of its life conditions? Climatologist Martin Beniston, that we meet later that day, made a study in 2014 [6] where he compared the evolution of climate in various cities in Europe, witnessing not only the general warming trend that have been both modeled and observed, but also considering the displacement of the average climate characteristics (temperature, humidity, etc.) from a region to another. This "climate analogue" study showed a displacement of climate of 15 kilometer per year, highlighting that Geneva now has the climate of Toulouse in the 1950s, while Toulouse inherited that of Madrid in the 1950s. Certainly, it is no wonder that a tree planted in Geneva, growing in Toulouse and then heading towards Madrid would face some difficulties in adaptation. And if you add the other factors such as the impact of urbanization, or the spreading of diseases facilitated by global warming, it gives an idea of the stress imposed on ecosystems. We share the chestnut tree's record with the climatologist, who validates it as a potentially valuable climate indicator [xiii].

-This is the strongest warming yes, it was already in February, in fact even in January! Amazing... In fact we - I mean the climate community - we use different sorts of indicators when we want to reconstruct past climates, before the time when we had instruments to record directly. And these sort of indirect indicators of changing climate can be extremely valuable. Your tree is a valuable indicator.

In the afternoon, our little group joins the lake. Close to the touristic site where the Geneva water jet is located, yet much more discreet, stand two erratic blocks emerged from the water called Pierres du Niton. It is said that they were involved in some local rituals in pre-modern times, as some inscription on the stones might attest, and later they were used as altimetric reference for Switzerland. More generally, these boulders were some of the first clues attesting that the climate could evolve over the ages, as remnants of a time when the region was buried under 700 meters of ice. When the Rhone glacier progressively retreated, some of the blocks carried by the ice stayed, puzzling the observers and giving birth to numerous local legends. What about our own "erratics"? What are they going to be in the future?, asks London-based artist Neil Cummings who is part of the tour. This question perfectly sets the tone for the investigation that will later unfold, attempting to build an anthropocene atlas that would be specifically related to the region of Geneva [xiv].

Two days after our visit, the marronnier officiel came into leaf. One year later, he died. Apparently, it was a mushroom attack along with a butterfly parasite that killed it, both of which are now fast spreading with the warming climate, threatening all the horse chestnut trees in the region. A fourth official tree was elected. It is still a marronnier, but the city's green service confirmed: one day they will not be adapted anymore, and a new tree species will have to be chosen. 


\title{
5 Concluding Remarks
}

\begin{abstract}
We should bring back to earth and reclaim everything that our lives are suspended on, and that ceaselessly tends to escape us. What we prepare is not an assault but a movement of continuous substraction, the attentive, soft and systematic destruction of all politics detached from the sensible world [xv] [7] Julien Coupat \& Eric Hazan.
\end{abstract}

While the scenes previously described each call for their own conclusions, some joint considerations can retrospectively be drawn. What becomes apparent is that specific conditions are necessary for an encounter to take place, although these encounters are of a different kind. The carefully built simulation event in Sciences Po, involving the strong engagement - also in terms of emotional engagement - of its participants, was necessary. So was the failure of the initial process, that forced them all to derail from the planned scenario, moving beyond the mere exercise and thus building a stronger relation to the current issues at stake. Similarly with Heike Vester and Maria Anna Hutter, their carefull observations of the whales and of the horse chestnut tree both require precise procedures that allow them to record that something else - something unexpected - is happening, and the high level of dedication necessary to sustain day to day relations with these beings certainly raise different affects in this prospect.

In terms of being affected, my own position is particular. It isn't equivalent to that of the students participating first-hand to the simulation, or to Heike Vester and Maria Anna Hutter doing daily observation on a tree or in a fjord. Still, what I experienced wasn't a mere transmission of information. I might say that for me these encounters happened also as a sensible experience of sharing knowledge in the context where it is produced, and in the company of those who allowed it to be experienced, leaving me reliant on their contribution. In fact, it is something that we have often been discussing with Sandrine in the course of our investigation $\boldsymbol{A}$ tale as a tool: the manner in which every person that we meet can operate for us as a guide, like the fisherman leading the narrator on the mountain in Poe's tale, sharing not only their stories but also contributing to stage the necessary conditions for a certain transmission of knowledge to happen. And these situations, along with the affects that they mobilize, are about as important as the stories themselves.

This process obviously relies on the context of the investigation itself, which encourages these forms of encounters. The notion of serendipity, described by Sacha Kagan as a "walker's wisdom" [8], emphasizes the necessary movement that puts us in contact with unexpected issues and beings and allows them to change our perspective. It requires a certain of disposition to attentiveness - something that Ana Lowenhaupt Tsing termed the "arts of noticing" [9] - and doesn't proceed from a predatory logic of coining down these issues and beings and capturing testimonies, rather favoring the possibility for them to step on our way while acknowledging their ability to somehow enlist us.

This is what happened in the Lofoten archipelago: after all, it is the killer whales who first burst into our investigation. This presence in itself was not sufficient, for we lacked the ability to interpret its importance, which is what Heike Vester then provided. Sandrine and I were always struck by the way the biologist, while describing how the whales are affected, was in fact repeatedly putting us in their position: "So imagine, you come, you swim like you have always done, then you come to this area and you hear that sound..." Both in that process of imagining (and sharing) the perspective of the whales themselves, and in her attempt to advocate for them by enlisting the fishermen and other actors in their defense, she perfectly plays the role of spokesperson proposed by Bruno Latour and Michel Callon [10]. And although we meet her at a time when her calls are still mostly unanswered, which makes her testimony even more striking, that situation will progressively evolve.

More could be said here about how the "voices" of non-human beings can be heard, and the official chestnut tree is a good example. I mentioned its potential role as indicator, but surely it does more than that. The marronnier officieel does more than just attesting what phenology and other methods in paleoclimatology mentioned by climatologist Martin Beniston - such as the famous ice core samples extracted from the ice sheet - already provide in a more extensive manner. In fact, what stroke me with 
the marronnier is precisely the fact that its budding record wasn't meant to serve for a scientific purpose. The effects of socially-caused global environmental changes, appearing in the midst of a local tradition already weaving nature and culture in an interesting fashion, then gave it a quite different take. Although the ice samples require very careful and precise procedures, they are still for many of us distant features, we may care for what their analysis tell us but we don't care for them, at least not in the way that we can care for a particular tree, and for a particular tradition. Maybe this is what making an alliance with this tree - as well as with the whales and many others - suggests: that building relations with other beings, developing narratives that bind us with them, gives us a sense of what it means when they are affected, for we know that we ultimately share a common fate.

I already mentioned the risk carried by highly covered controversies to flatten the complexity of the issues encountered in an investigation process. But that could also be said of many kinds of dominant representations and ideologies - progress and globalization being not the least - that operate in that context as powerful attractors [xvi]. They render invisible issues, practices, histories, they render invisible the countless beings and their world-making projects [9] that are stranger to their logic. We might call them attentional attractors, selecting the things we look at, as well as the way we look at them. It is always crucial to find ways to drift from these magnetizing forces, here joining voice with Yves Citton while calling for an ecology of attention [12], in a necessary attempt to regain a certain power on our attentional environments. This has been an important concern driving the realization of The Anthropocene Atlas of Geneva [xvii] during the past two years, as the interviews were not only focusing on mere "testimonies", but rather on the very capacity of each actor to produce representations that may challenge the very perception of our own investigation field. That is: to produce other attentional gestures [13].

In the case of A tale as a tool, the investigation process as defined with Sandrine, is also meant to keep this necessary openness. Indeed, we don't come to a region claiming straight ahead to investigate (for instance) the oil controversy and climate change effects. Instead we come with a heterogeneous object, a text of fiction, that the persons we meet can interpret in their own fashion, while being invited to relate it to their own practices, knowledge, and matters of concern. In that process, Poe's fiction of the maelström operates as a mediator object in our investigation, that allows for a certain encounter to take place. We might say that it also works as an attractor, but as a soft one: one that can be handled and re-appropriated by the people we meet, one that allows for a certain symmetry in the transmission of knowledges - while sharing stories on both sides-, and finally one that shouldn't overshadow the set of entangled relations that it is meant to both discern and enhance. In a different understanding of the term coined by Fredric Jameson, we might call this a "vanishing mediator" [14], as it gathers people around this new object while shifting the usual perspectives, before eventually fading out and letting room to the matters of concerns expressed and the new assemblages produced.

Yves Citton once highlighted the polysemic richness of the expression in French faire attention (Citton 2017), which isn't exactly equivalent to "paying attention". Faire attention à means "to be attentive to", which is understood here as an active process (literally "making attention"), but it means as well "being careful of" and "watching out". The arts of noticing are not only a practice of observing and acknowledging the existences of other entities and their world-making projects, it is also a practice of care and a call for prudence. For we shouldn't ignore that the modernization front keeps on advancing, brought to an accelerated and hyperbolic dynamic by the predatory logic of advanced capitalism, and threatening the relations with everything that sustain our very existence. Resisting the "upcoming barbary", as Isabelle Stengers summons us [3], first of all means enforcing the nets of solidarity relations that sustain life in all its forms. In this regard, whether we focus on the agency of non-human beings, or on the practices that participate in translating it and making it visible, anyway we get back to the fact that deep environmental mutations are occurring, and that in the perspective of becoming sensible to these changes, all voices are necessary and all translations welcome.

Funding: This research received no external funding.

Conflicts of Interest: The author declares no conflict of interest. 


\section{Notes}

i. Both of these authors obviously refer to the "Gaia theory" developed by chemist James Lovelock in the 1970s.

ii. Initiated by Sciences Po Paris and IDDRI (The Institute for Sustainable Development and International Relations), this event was entirely self-organized by the students of Sciences Po in June 2011, under the title "COP RW - et si ça s'était passé autrement?". We might call this a kind of role play, or a simulation, as it is being occasionally organized by associations related to the United Nations. For more information on the subject, see the article by David Goutx in the journal Négociations (2014): https://www.cairn.info/article.php?ID_ARTICLE=NEG_022_0017

iii. The program SPEAP - Master d'Experimentation en Arts Politiques, was launched at Sciences Po Paris in 2010 by philosopher and anthropologist Bruno Latour and co-directed by Valérie Pihet, gathering artists and researchers to experiment various forms of collaborative investigations. Link: blogs.sciences-po.fr/speap

iv. When it officially recognized itself as a collective, Save as Draft included Joffrey Becker, Axel Meunier, Sandrine Teixido, Simon Ripoll-Hurier and myself. At the time of the simulation, it also benefited from the contribution of Sylvain Gouraud, Filipe Païs and Eléonore Saintagnan. The contribution of Save as Draft to the simulation "COP RW" was part of the commissions proposed to the participants of the SPEAP program. It led to two performative interventions: the first one during the opening session of the simulation, based on interview material with scientists and negotiators who had taken part to the actual COP15, and the second one during the closing assembly, based on documents from the observation.

v. If we wanted to draw conclusions regarding the actual negotiation process, the outcomes of this exercise would prove quite limited since the goals, the complex calculation models, as well as the practical means at disposal were here highly simplified.

vi. A tale as a tool is a project of art and research developed since 2011 with anthropologist and author Sandrine Teixido. It led to numerous investigations, from the South of Brazil to the North of Norway, partnering with artistic and academic institutions and involving frequent collaborations: www.ataleasatool.com

vii. To know more about the research activities of biologist Heike Vester: https://ocean-sounds.org

viii. The sound can be heard on the website of $\boldsymbol{A}$ tale as a tool: https://ataleasatool.com/document/sonsseismic

ix. This moratorium, acknowledging the resistance of the local populations and the vulnerability of the marine ecosystems, was first planned until 2017. Despite the frequent attempts by the ruling conservative party (Høyre) to cancel it and the Arbeiderparti's turnaround on the subject, the status quo is still valid today, although it remains fragile. In the meantime, oil exploration and extraction is being performed along all the other coasts of Norway.

$\mathrm{x}$. Among other public events (exhibitions and conferences), this investigation maping process has been narrated in the series of performances MALSTRØM 68N: An inaccessible place at Théâtre de l'Usine, Geneva, in June 2015.

xi. This guided tour that I organized was part of a Seminar from the Pre-Doctorate/PhD series hosted by CCC Research-Based Master program at Geneva School of Art and design in March 2015. Involving a partnership with Chelsea College of Arts, University of the Arts London, this specific Seminar was also meant as one of the preliminary events to the research project The Anthropocene Atlas of Geneva (see note 14).

xii. For a more detailed report on the complex methods to evaluate the casualties provoked by this extreme event, see the report directed by INSERM for the World Health Organization "Improving 
Public Health Responses to Extreme Weather/ Heat-Waves - EuroHEAT": www.euro.who.int/_data /assets/pdf_file/0018/.../E91350.pdf

xiii In addition to global warming, other factors like the city's "heat island effect" might be taken into account to explain the evolution of the buddings, although in Geneva's context it is not expected to be a decisive factor.

xiv. The research project The Anthropocene Atlas of Geneva, supported by the Swiss National Fund for scientific research, was conducted at Geneva School of Art and Design from December 2016 to November 2018. The project director was Prof. Gene Ray, and the field researchers were Janis Schroeder, Kathleen McHugh Stevenson and myself. Its findings can be consulted here: https://head.hesge.ch/taag

$\mathrm{xv}$. The translation is mine.

xvi. Central to the studies of dynamic systems and chaos theory, the notion of "attractor" has been recently borrowed by Bruno Latour in his book Où atterrir? [11], where he proposes to map the re-distribution of the main political positions, in regard to the crisis of the modernization discourse.

xvii. See note 14 .

\section{References}

[1] Smithson, R. (1968). A Sedimentation of the Mind: Earth Projects. Artforum, September issue, p.44

[2] Latour, B. (2017). Facing Gaia: Eight Lectures on the New Climatic Regime. Cambridge, UK: Polity

[3] Stengers, I. (2009), Au temps des catastrophes. Résister à la barbarie qui vient. Paris: La Découverte

[4] Haraway, D.J. (2016). Staying with the trouble: making kin in the Chthulucene. Durham, NC: Duke University Press, https://www.cairn.info/article.php?ID_ARTICLE=NEG_022_0017

[5] Morton, T. (2013). Hyperobjects. Philosophy and Ecology after the End of the World. Minneapolis, MN: University of Minnesota Press.

[6] Beniston, M. (2014). European isotherms move northwards by up to 15kmyear-1: using climate analogues for awareness-raising. International Journal of Climatology, 34(6).

[7] Coupat, J. and Hazan, E. (2016). Pour un processus destituant : invitation au voyage. Libération, January 24 https://www.liberation.fr/debats/2016/01/24/pour-un-processus-destituant-invitation-au-voyage_ 1428639

[8] Kagan, S. (2012). Toward Global (Environ)Mental Change - Transformative Art and Cultures of Sustainability. Berlin: Heinrich Böll Stiftung

[9] Tsing, A.L. (2015). The Mushroom at the End of the World On the Possibility of Life in Capitalist Ruins. Princeton, NJ: Princeton University Press.

[10] Akrich, M., Callon, M. and Latour, B. (dir.). Sociologie de la traduction. Textes fondateurs. Paris: Les presses de l'École des Mines

[11] Latour, B. (2017). Où atterrir? Comment s'orienter en politique. Paris: La découverte.

[12] Citton, Y. (2017). The Ecology of Attention. Cambridge, UK: Polity

[13] Citton, Y. (2018). Learning to Derive: Financial Moves and Attentional Gestures in the Ecocidal Maelström. Movement Research Performance Journal, 51(1).

[14] Jameson, F. (1973). The Vanishing Mediator: Narrative Structure in Max Weber. New German Critique, 1.

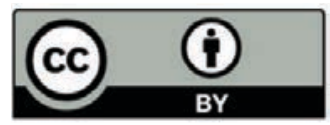

Copyright (c) 2019 by the authors. This is an open access article distributed under the Creative Commons Attribution License (https://creativecommons.org/licenses/by/4.0/), which permits unrestricted use, distribution, and reproduction in any medium, provided the original work is properly cited. 


\section{About the Author}

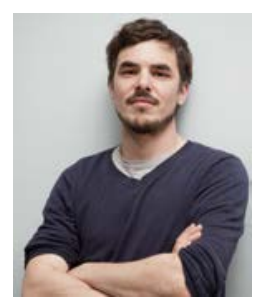

Geneva-based artist Aurélien Gamboni develops a practice of investigation, often involving field research and collaborations, and leading to multiple forms of installations, texts and lecture-performances. After having developed a long-term inquiry on The Conjurer by Hieronymus Bosch and the "ecology of attention", he is currently leading with Sandrine Teixido an investigation on Edgar Allan Poe's "maelström" and the cosmopolitics of nature, a multi-site inquiry taking place between Europe, Brazil and the United States. Aurélien Gamboni is a former curator of Forde independent art space (2006-2008), he took part in the artists and researchers collective Save as draft (2010-2012), and contributed as scientific collaborator to the SNF research project The Anthropocene Atlas of Geneva (2016-2018) at Geneva School of Art and Design (HEAD), where he currently teaches.

He took part in numerous exhibitions worldwide, including:If It's A Bird, Shoot It!, Sculpture Center, Long Island city, NY, 2008; The Big Picture, Tanya Leighton Gallery, Berlin, 2009; Weather Permitting, 9th Mercosul Biennial, Porto Alegre, 2013; Voglio Vedere le Mie Montagne, Museo MAGA, Gallarate, 2015; Guanabara Bay: Hidden Waters and Life, Museu de Arte Contempornea, Niteri, 2016; A tale as a tool, Centre de la Photographie Genve, 2017; Eblouissements, 5th Biennial of Lubumbashi (DRC), 2017. He was awarded a Swiss Art Award in both 2011 and 2016 . 